\title{
Moving the Audit Profession Forward
}

\author{
Philip Wallage
}

Received 4 October 2018

Accepted 5 October 2018

Published 18 October 2018

The 3rd International Conference of the Foundation for Auditing Research took place in June 2018 at Nyenrode Business University. The theme of the conference was "Moving the Audit Profession Forward - New Research and Best Practices". As in prior years we are pleased to report on the most important presentations and discussions in this special MAB issue.

\section{Positivist research}

The issue opens with a column written by our editorial board member Willem Buijink. Buijink clarifies the importance of different strands of auditing research. In this respect he refers to different disciplines (such as anthropology, economics, psychology or sociology) used to understand auditor's behavior) and different methodologies (case studies, field studies, lab experiments, field experiments, natural experiments, archival data based observational studies). According to Buijink the replicability of claims about the world is an indispensable requirement and a hallmark of positivist research. However, there is a group of auditing researchers that uses behavioral science or philosophy, arguing that testability of their claims is unimportant. This constructivist research approach is currently gaining influence among auditing researchers and having an increasing impact on auditing policy makers, regulators, oversight bodies and the press in the Netherlands. It is therefore that Buijink is very worried.

\section{Collaboration}

Next, based on discussions during the conference Philip Wallage, Jan Bouwens and Olof Bik note that collaboration in the auditing profession is key for improving audit quality: not just between academia and practice, but also between audit firms on the one hand and clients, regulators and policy-makers on the other hand. The auditors themselves must do a better job, but clients and other stakeholders will also have to take responsibility for the collective challenge the profession is facing: enhancing audit quality and restoring societal trust.
Next Preeti Choudhary discusses the mutual and 'interlaced' responsibility of auditors and their clients and related market outcomes. There are at least four parties that play an important role in ensuring high-quality audits and that make financial statements reliable to the investing public. The focus of her study is on management and the auditor's role, with less emphasis placed on the regulator and audit committee as both managers and auditors play important roles in ensuring high-quality audits that achieve reliable financial reporting.

\section{Preliminary results and new FAR projects}

During the conference, representatives of two research teams presented initial insights of their studies. Marike van Zanten and Luc Quadackers summarize their preliminary research findings. These presentations were provided by Therese Grohnert and Wim Gijselaers (concerning learning culture) and Anna Gold (regarding group audits). Furthermore, Olof Bik and Jan Bouwens, who are working on a FAR project in a so-called 'joint working group', presented their study on partner incentives and performance.

Pursuant Marike and Luc sketch the presentation of three new FAR-studies. First Mark Peecher presented his project entitled “Auditors' detection of fraud cues and management deception". Regulators and market participants increasingly express a desire to better understand auditors' capability to detect deception in management's representations and to identify new ways to enhance this capability. Therefore, this project deals with the fundamental issue of fraud detection and effective and accurate skepticism. A very interesting and emerging issue given the recent discussion in the Netherlands about the task and role of the auditor in detecting fraud and noncompliance with law and regulations.

In his project, Joseph Gerakos wants to go back to micro-economics and estimate supply and demand functions for the audit market. This will enable an analysis of the audit market and to assess its competitiveness and efficiency. Another important focal area of FAR is audi- 
ting in the owner-managed-business segment. The project presented by Jeroen Suijs is directly related to this segment and tries to answer the following question: 'does the owner-managed firm audit market serve a different purpose than, for example, the PIE audit market?'

\section{Global Trends}

The next paper summarizes the presentation of Janine van Diggelen. She provided her personal insights and perspectives on global trends in audit quality, supervision and standard setting. She emphasizes that root cause analysis and change programs should focus on culture, the business model, sufficient talent, process and project management to support the strategies of delivering high quality audits throughout the firms and the profession.

\section{Knowledge Gap}

Finally Olof Bik and Jan Bouwens summarize the key note speech by Steve Salterio about overcoming barriers in communication between academics and practice: Mo- ving beyond the Lab. After all, the aim of academics is to effectively scientifically inform policy-making in and around the profession.

In short, academics and practicing auditors can learn a lot from each other on this front. In his presentation, Salterio gives a good example of a practical question that can be answered by academics because they possess research techniques that can determine causal relationship. For instance, an academic will ask firms to perform some audits with a new registration system and some without it. This will allow the researcher to determine whether the improvement in audit quality can be attributed to the introduction of the engagement registration system. Without this research a wrong policy measure might be taken.

Concluding, I am hopeful that this MAB-FAR issue will contribute to a further open multi-stakeholder dialogue as created during the 3rd FAR conference. All of the participants agree that audit quality can be improved if academics and the audit industry join forces in examining audit practices. This issue of MAB demonstrates the added value this collaboration can have.

Last but not least, we are grateful to our guest editors Olof Bik, Jan Bouwens and Judith Künnike for contributing to this special issue.

- Prof. dr. Ph. Wallage RA is a professor of Auditing at Vrije Universiteit Amsterdam (VU) and Universiteit van Amsterdam (UvA). 